\title{
Sepsis Needs Follow-Up Studies in Intensive Care Units- Another Avenue for Translational Research
}

\author{
Carlota Saldanha* and António Messias** \\ *Institute of Molecula Medicine, Institute of Biochemistry, Faculty of Medicine, University of Lisbon, Portugal \\ **Director of Intensive Care Unit in Hospital Beatriz Ângelo. Loures, Portugal
}

Submission: March 28, 2017; Published: May 02, 2017

*Corresponding author: Carlota Saldanha, Institute of Molecula Medicine, Institute of Biochemistry, Faculty of Medicine, University of Lisbon, Portugal, Email: carlotasaldanha@medicina.ulisboa.pt

Abstract

Sepsis characteristics were highlight in this mini review in order to call attention for a complex, age- independent, acute disease faced suddenly by the human body under infection or traumatic stimuli. It may follow surgical intervention, traumatic accident or exposure to an infectious agent. Timely diagnosis and accurate stratification of the severity of sepsis are needed to understand the molecular mechanisms involved in this pathophysiology and reduce mortality. In order to obtain these achievements follow-up studies need to be conducted in intensive care units under translational research.

Keywords: Sepsis, Intensive care unit, Inflammation, Nitric oxide, Acetylcholinesterase

\section{Mini Review}

The high mortality verified worldwide in patients with sepsis in intensive care units (ICU) is a sad social problem that needs to be solved. Sepsis is still a fatal condition besides the reporter of many biomarkers of diagnostic and prognostic. "In the United States was estimated the occurrence of 751,000 cases of severe sepsis per year (3.0 cases per 1,000 population and 2.26 cases per 100 hospital discharges), of whom 383,000 (51.1\%) received intensive care and an additional 130,000 $(17.3 \%)$ were ventilated in an intermediate care unit or cared for in a coronary care unit. Mortality was $28.6 \%$ or 215,000 deaths nationally. The average costs per case were $\$ 22,100$, with annual total costs of $\$ 16.7$ billion nationally. The Incidence was projected to increase by $1.5 \%$ per annum [1] from the onset of sepsis syndrome, an imbalance between pro-inflammatory and anti-inflammatory mechanisms occurs. The intensity and duration of the inflammatory response has been closely related with mortality, since once out of control inflammation leads to massive production of pro-inflammatory cytokines, which in turn leads to coagulation disorder, tissue injury, multiple organ dysfunction, and ultimately to death. All studies conducted until now highlight difficulties and inability to address the heterogeneity that characterizes sepsis.

Simultaneously inflammatory response is triggered as well others molecular mechanism involving hormonal metabolic control, macro and microcirculation controls are call to react changing their homeostasis [2]. At microcirculation blood flow through small vessels favor gas exchanges such as oxygen and nitric oxide (NO) with carbon dioxide, deliver nutrients and remove metabolites and waste products [3]. Erythrocytes deliver $\mathrm{O}_{2}$ and $\mathrm{NO}$ in lower oxygen partial pressure $\left(\mathrm{PaO}_{2}\right)$ and scavenge them at high $\mathrm{PaO}_{2}$ [3]. The ability of erythrocyte to deliver or retain NO depends on the membrane AChE enzyme activity and protein conformations [4]. Microcirculation hemodynamic influences blood pressure, hemorheology and micro vascular cells wall participate in inflammation. When microcirculation starts to be compromised severe uncontrolled outcomes appear. Impaired sensitivity of endothelial cell (EC) in microvasculature to vasoconstriction/ vasodilating substance is a signal of endothelium dysfunction [5]. This is worsening by the decrease in blood flow rate consequently to decreased erythrocyte deformability and increase erythrocyte aggregation [5]. So, there are created conditions for a thigh permanence of white blood cells (WBC) in the EC surface [5]. Under inflammatory stimuli the WBC decrease its rolling velocity, increasing adherence and transmigration until the focus of tissue injury [6]. Neutrophils recruitment to sites of infection is a critical element of the innate immune response, being the cells that migrate first to an infectious site responding to chemo attractants factors and cytokines. Neutrophils are able to kill microorganisms by releasing bactericidal agents like oxygen and nitrogen reactive species. The neutrophils, in addition also release, cytokines and chemokines which enhance the recruitment and activation of immune cells. During the pro- 
inflammatory phase, cytokines released from innate immune system cells contribute to endothelial dysfunction by different ways, including the interference with the expression of iNOS that originates nitric oxide (NO) increase. The current knowledge on the mechanism by which NO modulates vascular function/ dysfunction in sepsis is limited.

In sepsis, the initiating stimuli of systemic inflammation are often bacterial components which induce the secretion of pro-inflammatory cytokines from cells of the immune system [2]. The release of those pro-inflammatory mediators in the central nervous system at the onset of sepsis leads to neuronal loss [7]. This finding is on the base of cognitive impairment with electroencephalographic changes observed in some sepsis survivors [7].

Sepsis presents an acute pattern of response of the immune system to the injury with a myriad of changes in mediators of inflammation, hemostasis and metabolism [8]. Insulin resistance in sepsis is largely attributed to the higher levels of TNFalpha, IL-1, and IL-6 [8]. Insulin, glucose and lactate levels are associated with the clinical sepsis score APACHE-II values [9]. In response to endotoxin, the body exhibits transient systemic insulin resistance, in an attempt to spare glucose for utilization by immune cells [10]. Persistent insulin resistance appears in sepsis because of the nitrosylation or nitration of its receptor [10]. Insulin resistance can be eliminated in some patients with sepsis by continuous intravenous infusion of insulin in the form of glucose-insulin-potassium (GIP) regimen that improves survival [11]. This is presumably related with decreased expression of NF-kB, IL-1 and IL-6 [11]. However, the degree of cell dysfunction resulting from the hyperglycaemia (related to insulin resistance) generates a multitude of changes in metabolic, hemostasis, and microcirculatory blood flow in patients unable them to survive [12]. Hyperglycemia generates imbalanced oxidant and antioxidant pathways, generating high levels of oxygen and reactive nitrogen species accompanied by abolished plasma antioxidant capacity [13]. This increased oxidative state contributes to the endothelial dysfunction with over expression of inducible nitric oxide syntheses (iNOS) and high release of NO to the lumen [14]. NO scavenged by erythrocyte impaired the deformability that clogs capillaries in the microcirculation [15].

Microcirculation issues gained increased importance in sepsis. The introduction of bedside techniques into clinical practice allow functional hemodynamic monitoring showing microcirculatory failure associate to adverse outcomes in patient's sepsis at intensive care unit (ICU) [16]. The complexity of the systemic inflammatory response in different phases of sepsis, the lack of progress in treatment and also in patients' diagnosis and stratification demonstrate the lack in knowledge of sepsis pathophysiology. The approach of measuring a simple inflammatory marker is not enough to assess patients' status. To direct appropriate therapy to individual patient and to improve diagnosis and stratification of patients it is necessary to identify the inflammatory response profile of different patients using multiple markers, and to unveil the relation of those profiles with the disease severity. To achieve that an accompanying follow-up evaluation of inflammatory, hemostatics, biorheological and microcirculatory markers is needed. In this perspective, the probability of an individualized treatment based on clinical and laboratory evaluations will be higher.

\section{References}

1. Angus DC, Linde-ZWT, Lidicker J, Clermont G, Carcillo J, et al. (2001) Epidemiology of severe sepsis in the United States: analysis of incidence, outcome, and associated costs of care. Crit Care Med 29(7): 1303-1310.

2. Hotchkiss RS, Karl IE (2003) The pathophysiology and treatment of sepsis. N Engl J Med 348(2): 138-150.

3. Ellsworth M, Ellis CG, Goldman D, Stephenson AH, Dietrich HH, et al. (2009) Erythrocytes: Oxygen sensors and modulators of vascular tone. Physiology (Bethesda) 24: 107-116.

4. de Almeida Lopes JP, Freitas-Santos, Saldanha C (2009) FibrinogenDependent Signaling in Microvascular Erythrocyte Function: Implications on Nitric Oxide Efflux. J Memb Biol 231(1): 47-53.

5. Barvitenko NN, Aslam M, Filosa J, Matteucci E, Nikinmaa M, et al. (2013) Tissue oxygen demand in regulation of the behaviour of the cells in the vasculature. Microcirculation 20(6): 484-501.

6. Tousoulis D, Simopoulou C, Papageorgiou N, Oikonomou E, Hatzis G, et al. (2014) Endothelial dysfunction in conduit arteries and in microcirculation. Novel therapeutic approaches. Pharmacol Ther 144(3): 253-267.

7. Semmler A, Frisch C, Debeir T, Ramanathan M, Okulla T, et al. (2007) Long-term cognitive impairment, neuronal loss and reduced cortical cholinergic innervation after recovery from sepsis in a rodent model. Exp Neurol 204(2): 733-740.

8. Rittirsch D, Flierl MA, Ward PA (2008) Harmful molecular mechanisms in sepsis. Nat Rev Immunol 8(10): 776-787.

9. Nakamura M, Oda S, Sadahiro T, Watanabe E, Abe R, et al. (2012) Correlation between high blood IL-6 level, hyperglycemia, and glucose control in septic patients. Crit Care 16(2): R58.

10. Moreira APB, Alfenas RCG (2012) The influence of endotoxemia on the molecular mechanisms of insulin resistance. Nutr Hosp 27(2): 382390.

11. van den Berghe G, Wouters P, Weekers F, Verwaest C, Bruyninckx F, et al. (2001) Intensive insulin therapy in Critically ill patients. N Engl J Med 345(19): 1359-1367.

12. Das UN (2002) Insulin and inflammation: further evidence and discussion. Nutrition 18(6) 526-527.

13. Cowley HC, Bacon PJ, Webster NR, Jones JG, Menon DK ( 1996) Plasma antioxidant potential in severe sepsis: a comparison of survivors and non-survivors. Crit Care Med 24(7): 1179-1183.

14. Han YJ, Kwon YG, Chung HT, Lee SK, Simmons RL, et al. (2001) Antioxidant enzymes suppress nitric oxide production through the inhibition of NF-kappa B activation: role of $\mathrm{H}(2) \mathrm{O}(2)$ and nitric oxide in inducible nitricoxide synthase expression in macrophages. Nitric Oxide 5(5): 504 - 513.

15. Bateman RM, Jagger JE, Sharpe MD, Ellsworth ML, Mehta S, et al. (2001) Erythrocyte deformability is a nitric oxide-mediated factor in decreased capillary density during sepsis. Am J Physiol Heart Circ Physiol 280(6): H2848-H2856.

16. Gruartmoner G, Mesquida J, Ince C (2017) Microcirculatory monitoring in septic patients: Where do we stand? Med Intensiva 41(1): 44-52. 
This work is licensed under Creative Commons Attribution 4.0 License

DOI: 10.19080/NAPDD.2017.01.555555
Your next submission with Juniper Publishers will reach you the below assets

- Quality Editorial service

- Swift Peer Review

- Reprints availability

- E-prints Service

- Manuscript Podcast for convenient understanding

- Global attainment for your research

- Manuscript accessibility in different formats ( Pdf, E-pub, Full Text, Audio)

- Unceasing customer service

Track the below URL for one-step submission https://juniperpublishers.com/online-submission.php 